\title{
Health-seeking behaviour in the city of Lubumbashi, Democratic Republic of the Congo: results from a cross-sectional household survey
}

Mukalenge F Chenge ${ }^{1 *}$, Jean Van der Vennet ${ }^{2}$, Numbi O Luboya ${ }^{1}$, Veerle Vanlerberghe ${ }^{2}$, Mala A Mapatano ${ }^{3}$

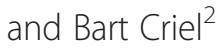

\begin{abstract}
Background: Concerns about the occurrence of disease among household members generally initiate treatment-seeking actions. This study aims to identify the various treatment-seeking options of patients in Lubumbashi, analyze their health-seeking behaviour, identify determinants for the use of formal care, and analyze direct health care expenditure.
\end{abstract}

Methods: A cross-sectional survey of households in Lubumbashi was conducted in July 2010. Information was collected from a randomly selected sample of 251 households with at least one member who had been ill in the 2 weeks preceding the survey.

Results: Frequently used initial treatment-seeking options consist of self-medication based on modern medicines (54.6\%), the use of first-line health services (23.1\%) and hospitals (11.9\%), with a perceived effectiveness of 51\%, 83\% and $91 \%$ respectively. If people go for a second option, then formal health care services are most often preferred. The majority (60\%) of patients' spontaneous itineraries reflect the expected functioning of a local health care system, with a patient flow characterised by the use of a first line health facility prior to the use of hospital-based services. Chronicity of the disease is the main determinant of seeking formal care. Analysis of care expenditure reveals that drugs are the only line of expenditure in the informal system and the main source of expenditure in the formal system; costs do not discriminate between first-line health services and hospitals, and the payment system is regressive since the poorest patients pay the same amounts as the richest.

Conclusions: This study points to the importance of self-medication as the first therapeutic option for the majority of patients in Lubumbashi, whatever the nature of the health problem. There is a lot of room to rationalise this practice. Although formal care is not common initial therapeutic option, it is the source of care most patients turn to, especially when they believe having a chronic disease. Patients' itineraries in this urban environment are complex; health managers should try and deal with this reality. Finally, our study indicates that poor patients face the same level of out-of-pocket payments as the more wealthy ones, hence the need for more equitable health care financing arrangements.

Keywords: Democratic Republic of the Congo, Lubumbashi, Urban health, Health care system, Health-seeking behaviour, Health service utilization, Health care costs

\footnotetext{
* Correspondence: fchenge@hotmail.fr

${ }^{1}$ Ecole de santé publique, Université de Lubumbashi, P.O. Box 1825,

Lubumbashi, RD, Congo

Full list of author information is available at the end of the article
} 


\section{Background}

Concerns about the occurrence of disease among household members generally create a demand for treatment and initiate treatment-seeking actions. Decisions are then taken and therapeutic options are reviewed. There is a vast literature on the nature and determinants of these therapeutic options, including in developing countries. Therapeutic options are categorized into the use of public versus private, private for profit versus private not for profit, formal versus non-formal, modern versus traditional and first-line versus second-line health care services [1-6]. The choice of therapeutic options is determined by demographics, socio-economic concerns, health problems, and the features of the various health services [7].

While studies are published on health seeking behaviour in rural sub-Saharan African settings, very few are devoted to urban environments. Those that exist were published before 2000 [1,8-10], hence the need for more recent data. This scarcity of information limits our understanding of the health-seeking behaviour of patients in urban contexts, i.e. one in which the health care system is characterized, among other things, by a diversity of supply [2,11-14] and by an ongoing epidemiological transition with an increase of non communicable diseases.

The DR Congo (Democratic Republic of the Congo) is currently conducting a health system reform. Given the contextual differences between rural and urban environments, the city of Lubumbashi has been chosen to pilot the reform in Congolese urban settings.

The epidemiological profile of the DR Congo is characterized by endemic diseases like malaria, typhoid fever, tuberculosis, and leprosy. While outbreaks of measles, Ebola hemorrhagic fever, whooping cough, and cholera continue to strike, one observes that non-communicable diseases like diabetes, hypertension, and sickle cell anaemia are on the rise [15]. The ratios of infant and maternal mortality are among the highest in the world, with 97 infant deaths per 1000 live births [16] and 549 maternal deaths per 100,000 live births [17].

This general picture of morbidity and mortality in the DR Congo also prevails in the city of Lubumbashi. In 2002, the Observatory of Urban Change (Observatoire du Changement Urbain) of the University of Lubumbashi published a report on the health profile of the inhabitants of Lubumbashi [18]. According to this report, morbidity is dominated by parasitic and infectious diseases. Malaria tops the disease profile at the community level $(67 \%$ of disease cases), as well as in health care facilities (over $20 \%$ of outpatients and inpatients). It is also the pathology most frequently responsible for fever in pregnant women [19] and anaemia (the most common cause of mortality, especially among children under five) [18,20]. In Lubumbashi, complications during pregnancy are the most common cause of maternal mortality [21]. The prevalence of hypertension in the population is estimated at 13\% [22].

Despite the magnitude of health problems in Lubumbashi, and despite the availability and diversity of the formal health care delivery system [14], the utilization of curative care in first-line health services barely reaches 0.4 new cases per inhabitant per year [23]. This relatively low utilisation of curative care in formal health services may be explained by financial constraints which lead patients to opt for the use of informal care providers. Given that no significant form of social health protection arrangement is in place in Lubumbashi, out of pocket payment is the common mode of paying for health care.

This study aims to identify the therapeutic options used by the inhabitants of Lubumbashi, analyze individuals' therapeutic itineraries, identify the determinants of the use of formal care, and analyze direct health care expenditures. Its purpose is to help urban health authorities to set evidence-based priorities in terms of reorganizing health care delivery in the city. Finally, this study is more comprehensive than previous ones limited to study the formal health care sector $[14,23]$.

\section{Methods}

\section{Study setting}

The study was conducted in the city of Lubumbashi in the south-eastern part of the DR Congo. The size of the population was estimated at 2 million inhabitants in 2010. In 2010, Lubumbashi counted nine Health Districts (HDs), which were divided into 107 unequally distributed Health Areas (HAs). The formal health facilities consisted of nine hospitals of 50 beds or more, more than 20 small-sized hospitals (counting less than 50 beds), and an extensive network of First-Line Health Services (FLHS) [14].

\section{Study design}

A cross-sectional study was conducted through a rapid household survey from the $21^{\text {st }}$ to the $24^{\text {th }}$ July 2010 . We carried out semi-structured interviews with the heads of household or any other household member able to answer questions.

\section{Sampling}

Sample size was calculated with the aim to detect a $50 \%$ formal health care use among household members who experienced a health problem within the two weeks preceding the survey (accuracy 10\%, alpha 5\%, power $80 \%)$. The sample size was sufficient to detect an association of 2.5 between determinants and the outcome with a power of $85 \%$. We used a two-stage cluster sampling (HA cluster and simple random sampling of households). The sample size was corrected for the design effect by multiplying it by two and by increasing it with $20 \%$ to 
account for inaccuracies and non-respondents. The calculated sample size representing the minimal number of households to be surveyed was 231 corresponding to 33 clusters of seven households. The inclusion criteria in the survey were: a household in which someone had been ill within two weeks preceding the survey and in which there was a person able to answer questions. Houses were revisited once (the next day) when nobody was at home during the survey visit.

In practice, we randomly selected three HAs in each HD with less than $10 \mathrm{HAs}$, four HAs in HDs with 10 to 14 HAs, and five HAs in HDs with at least 15 HAs. Based on a detailed map of each selected HA, we randomly selected seven households corresponding to the minimum number of households to be surveyed by HA. These seven households were each visited and investigated if they met the inclusion criteria. When the household lacked anyone who had been ill or who was able to respond to the investigator, the investigator was instructed to move to the first household to the right when facing the previous one, and to continue this itinerary until he found a household that met the inclusion criteria. If a person had developed more than one episode of disease during the two weeks preceding the survey, the focus was on the most recent one [4]. If several people were ill in a same household, one household member was chosen at random, drawing a number from a bag, for further investigation.

\section{Data collection}

A semi-structured interview guide was developed in order to list all therapeutic options and possible patient itineraries. By therapeutic options, we mean all actions taken to cope with the disease; by itineraries, we mean their sequence within a given disease episode [4,24]. As with most health problems, the recollection of the details of seeking treatment quickly fades, a recall period of two weeks was therefore considered $[1,4,25]$. The health problem may have appeared within the timespan of these two weeks, or may have started before but continued during at least part of the 2-week recall period [24].

Information about therapeutic options was classified as follows:

- Traditional medicine (self-medication based on traditional remedies or the use of a traditional healer).

- Self-medication based on modern medicines available at home, bought at the market or in a neighbourhood pharmacy.

- Any occasional use of the services of a selfemployed health professional (private doctor or nurse) at his home or at the patient's home.

- Any use of an established first-line health service (i.e. any public or private facility providing ambulatory curative and preventive care, and able to handle normal deliveries, regardless of what the facility was called: health centre, medical centre, dispensary, etc.).

- Any public or private hospital capable of providing major general surgery and hospitalization, regardless of what it was called: hospital, clinic, referral health centre, etc.

The interviewer also collected information related to variables that could explain the choice of a given therapeutic option. Variables reported by the respondent included the patient's age and sex, household size, number of parents in the household, education and identity of the main breadwinner, nature of the disease, and acuteness or chronicity of the disease (as reported by interviewee). Other variables were assessed through observation, such as connection to electricity and water, type of pavement of the house, and household wealth (possession of following assets: mobile phone, bicycle, motorcycle, or car). The interviewer also asked for the financial expenditure for the care of the health problem.

The interview guide was designed in French (the official language of the DR Congo) and then translated into Swahili by a person familiar with both languages. The Swahili version of the guide was translated back into French by another person who had perfect mastery of the two languages for a final check of the accuracy of the translation. The French and Swahili versions were used throughout the survey, depending on the language preference of the respondent.

Data collection was conducted by 12 nurses; all were members of the district management teams of the nine HDs of Lubumbashi. These nurses were not involved in providing curative care in the health facilities of their respective HDs. They were trained for the purpose of the survey and the interview guide was pre-tested.

\section{Data analysis}

Two trained persons simultaneously recorded all data in an Epi Info database. Statistical analyses were performed using STATA software IC/11 at a statistical significance level of $5 \%$. Therapeutic options were grouped into two categories: informal care (traditional medicine and self-medication based on modern drugs) and formal care (use of a private health professional at his home or at the patient's home, use of a first-line health service or a hospital).

Referring to other similar health-seeking behaviour studies $[1,4,26]$, we grouped the notified health problems into three main categories: malaria syndrome, including malaria and unspecified fever; respiratory tract syndrome: i.e. common colds, cough, and acute respiratory infections (bronchitis, pneumonia); and Water, Hygiene and Sanitation (WHS) complex: health problems related to water, hygiene, and sanitation (diarrhoea, gastro-intestinal 
diseases, abdominal pain, and dermatitis). We added a fourth category "others", which combined health problems not fitting the three first syndromes: for instance, gynaecological and obstetrical problems, and chronic conditions (e.g., diabetes and hypertension).

By adapting the classification of Petit [27], we grouped the main income-generating activities of the head of household into four categories: inactive; paid on a daily basis (taxi drivers, farmers, informal traders); salaried employees and independent self-employed workers (masons, carpenters, cabinet-makers, joiners, plumbers, designers, and small business owners); and corporate executives and professionals (e.g., lawyers and doctors).

In line with the study environment and with reference to other similar studies [1,27], the socioeconomic status of each household was assessed using an index calculated on the basis of weighted categories (Table 1). The score generated varies from 3 to 36.5 and allowed us to classify households into quintiles of socio-economic welfare $[1,16]$.

Searching for factors that might influence the initial choice of a therapeutic option in the context of Lubumbashi (Figure 1), we first performed a bivariate analysis with all relevant independent variables. Odds Ratios and their respective 95\% Confidence Intervals (CI) were calculated. A binary logistic General Estimating Equation model was constructed from the variables that were significant in the bivariate analysis and these non-significant variables that were deemed important or potential confounders on a priori grounds [28]. This kind of model takes into account the clustering of data [29].

To appreciate the costs of care, we calculated median costs and used $95 \% \mathrm{CI}$ for comparison purposes.

\section{Ethical considerations}

The study protocol was reviewed and approved by the medical ethical committee of the UNILU (University of Lubumbashi) on 5 July 2010 (Approval No.: UNILU/ CEM/009/2010) and the IRB (Institutional Review Board) of the Institute of Tropical Medicine in Antwerp on 7 July 2010 (IRB Number: 10204719). No harm was anticipated to respondents. Interviewers were instructed to explain in advance the objectives of the study and highlight the anonymous and confidential use of collected data. Informed consent of respondents was sought, and signed consent forms were obtained in advance.

\section{Results}

A total of 268 households met the inclusion criteria; one person in each household was interviewed. Seventeen patients (6.3\%) did not take any therapeutic action for their health problem. We did not further analyze data from these households. Ultimately, the analysis focused on a sample of 251 households.
Table 1 Design of socio-economic status assessment of surveyed households, Lubumbashi, 2010

\begin{tabular}{|c|c|}
\hline Variables & Score \\
\hline \multicolumn{2}{|l|}{ Household size } \\
\hline $1-5$ persons & 3 \\
\hline 6-10 persons & 2 \\
\hline$\geq 11$ persons & 1 \\
\hline \multicolumn{2}{|l|}{ Number of parents in the household } \\
\hline 1 & 1 \\
\hline 2 & 3 \\
\hline \multicolumn{2}{|l|}{ Level of education of household head } \\
\hline Illiterate & 0.5 \\
\hline Incomplete primary education & 1 \\
\hline Complete primary education & 1.5 \\
\hline Incomplete secondary education & 2 \\
\hline Complete secondary education & 2.5 \\
\hline Incomplete Higher education & 3 \\
\hline Complete Higher education & 3.5 \\
\hline \multicolumn{2}{|l|}{ Main income generating activity of the household head } \\
\hline Inactive & 0.5 \\
\hline Paid on a daily basis & 1 \\
\hline Salaried employees and independent workers & 2 \\
\hline Corporate executives and professionals & 4 \\
\hline \multicolumn{2}{|l|}{ Assets ownership of the household ${ }^{a}$} \\
\hline Cell phone & 1 \\
\hline Bicycle & 2 \\
\hline Motorcycle & 4 \\
\hline Car & 6 \\
\hline \multicolumn{2}{|l|}{ Characteristics of the habitat $^{a}$} \\
\hline Connection to electricity & 2 \\
\hline Ground pavement & 4 \\
\hline Connection to water & 4 \\
\hline Total score range & $3-36.5$ \\
\hline
\end{tabular}

The score is 0 when the household does not have the item.

Profile of surveyed households and patients

Table 2 presents the main characteristics defining the profile of households and patients surveyed.

\section{Reported health problems}

The frequencies of the four groups of health problems reported by respondents are shown in Table 3: of 251 patients, $34.3 \%(\mathrm{n}=86)$ of patients experienced a malaria syndrome, $27.9 \%(\mathrm{n}=70)$ a respiratory tract syndrome and $17.1 \%(n=43)$ suffered from diseases related to the WHS complex. In addition, $79.4 \%$ of respondents in the category "other" believed that the diseases they reported were chronic problems, and $69.8 \%$ of patients with a disease duration exceeding 2 weeks were placed in the 


\section{Independent variables $\quad$ Dependent variable}

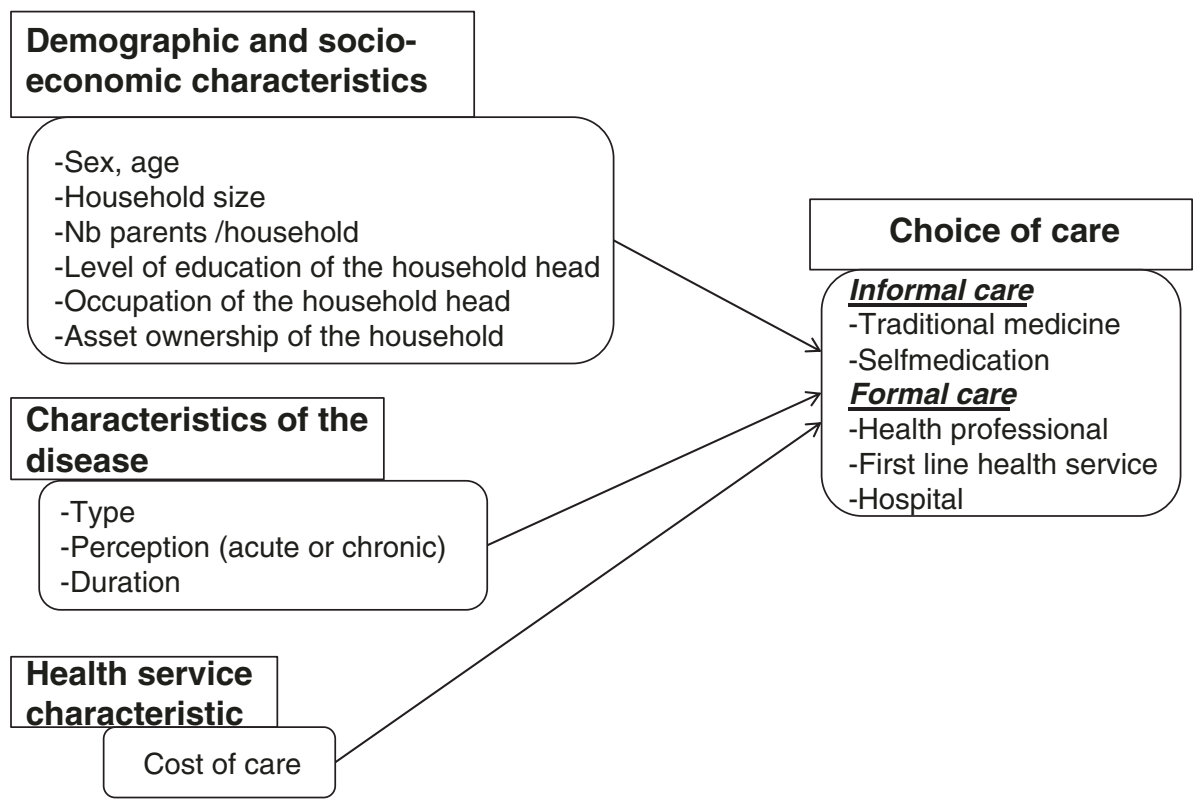

Figure 1 Factors influencing the choice of care: conceptual framework adapted from Develay et al. [1] and Kroeger [7].

category "other", which includes recognized chronic conditions such as diabetes and hypertension.

Additionally, by examining responses about acuteness/ chronicity of disease, as reported by interviewee, and the actual duration of disease reported, we observed that only $5.9 \%(2 / 34)$ of the diseases that interviewee reported to be chronic lasted for less than 2 weeks and 25.6\% (11/43) of conditions that lasted for more than 2 weeks were considered by respondents to be acute problems.

\section{Therapeutic options and patients' itineraries}

Figure 2 presents the different therapeutic options and describes the various patient itineraries in search of care.

Self-medication based on the use of modern drugs was the initial most widely used option (54.6\%), followed respectively by the use of a FLHS (23.1\%) and a hospital (11.9\%). Traditional medicine as an initial therapeutic option represented less than $5 \%$ of patient itineraries.

We also note that 90 of the 251 patients (35.8\%) used more than one therapeutic option; patients described as many as 15 different trajectories from their first to their second option. For $80 \%$ of these 90 patients, informal care was the initial therapeutic option. The shift from informal care as initial option to formal care as second option was $91.7 \%$ (66/72), compared with $33.3 \%(6 / 18)$ in the opposite direction; this difference was statistically significant $(p<0.001)$. In $60 \%$ of cases $(54 / 90)$, the shift from first to second therapeutic option is consistent with a health-seeking behaviour that health system planners would qualify as "rational" (i.e. starting from self-medication, progressing next to the use of ambulatory care offered by an individual health professional or a first-line health facility, and thereafter the use of a hospital).

Figure 2 also shows that $40.6 \%$ of patients surveyed $(102 / 251)$ used formal health care services as their first therapeutic option. Their main point of entry into the formal system was a FLHS in 56.5\% of cases (95/168), a hospital in $30.4 \%(51 / 168)$ of cases and a self-employed private health professional in $13.1 \%(22 / 168)$ of cases.

Furthermore, when we evaluated the perceived effectiveness (on the basis of statement of cure) of each therapeutic option, it appeared that $53.8 \%$ of patients felt cured at the time of the survey. Of these, $65.2 \%(88 / 135)$ reported this after having used the initial therapeutic option; $28.1 \%$ (38/135) and 6.7\% (9/135), respectively, reported feeling cured after the second and the third options. The respective cure rates for the initial therapeutic option were $42.9 \%$ (3/7) for traditional medicine, $51.4 \%(36 / 70)$ for selfmedication, $71.4 \%$ (5/7) for a self-employed private health professional operating outside a health facility, $82.8 \%$ $(24 / 29)$ for FLHS, and $90.9 \%$ (20/22) for a hospital.

Factors influencing the choice of the therapeutic option: bivariate and logistic regression analyses

Table 4 shows the results of the bivariate analysis and indicates that only the chronicity of disease was significantly associated with the choice of formal health care $(p=0.007)$. When variables were introduced into a logistic 
Table 2 Key characteristics of households surveyed, Lubumbashi 2010

\begin{tabular}{|c|c|c|}
\hline Variables & $\mathrm{n}=\mathbf{2 5 1}$ & $\%$ \\
\hline \multicolumn{3}{|l|}{ Household size } \\
\hline $1-5$ & 74 & 29.5 \\
\hline $6-10$ & 129 & 51.4 \\
\hline$\geq 11$ & 48 & 19.1 \\
\hline \multicolumn{3}{|l|}{ Number of parents in the household } \\
\hline 1 & 6 & 2.4 \\
\hline 2 & 245 & 97.6 \\
\hline \multicolumn{3}{|l|}{ Level of education of household head } \\
\hline Illiterate & 4 & 1.6 \\
\hline Primary education & 47 & 18.7 \\
\hline Secondary education & 145 & 57.8 \\
\hline Higher education & 55 & 21.9 \\
\hline \multicolumn{3}{|l|}{$\begin{array}{l}\text { Main income generating activity of } \\
\text { the household head }\end{array}$} \\
\hline Inactive & 29 & 11.6 \\
\hline Paid on a daily basis & 77 & 30.7 \\
\hline Salaried employees and independent workers & 139 & 55.3 \\
\hline Corporate executives and professionals & 6 & 2.4 \\
\hline \multicolumn{3}{|l|}{ Socioeconomic status of the household } \\
\hline 1 (Poorest) & 52 & 20.7 \\
\hline 2 & 60 & 23.9 \\
\hline 3 & 39 & 15.5 \\
\hline 4 & 52 & 20.7 \\
\hline 5 (Richest) & 48 & 19.1 \\
\hline \multicolumn{3}{|l|}{ Age of patients surveyed (years) } \\
\hline$\leq 4$ & 61 & 24.3 \\
\hline$\geq 5$ & 190 & 75.7 \\
\hline \multicolumn{3}{|l|}{ Sex of patients surveyed } \\
\hline Male & 105 & 41.8 \\
\hline Female & 146 & 58.2 \\
\hline
\end{tabular}

regression model, "chronicity of disease" remained the only variable that determined the choice formal health care (adjusted $\mathrm{OR}=2.44,95 \% \mathrm{CI}=1.24$ to $4.78, \mathrm{p}=0.01$ ). This means that patients used formal health care as one of the options for diseases reported as chronic 2.44 times more often than for diseases reported as acute.

\section{Analysis of the direct financial costs associated with the use of various therapeutic options}

Table 5 presents the expenses related to each single therapeutic option, according to different components of care. It does not capture the totality of costs because certain episodes of disease were still ongoing at the time of the survey. Drugs were the only expenditure in case of use of the informal health care system and they were the greatest expense when patients used the formal system. Costs were significantly higher in FLHS and in hospitals than in the case of patients that employed selfmedication or used traditional medicine. Within the formal system, FLHS expenditures were lower than hospital expenditures; however, the observed differences were not statistically significant with the exception of transportation fees to an FLHS, which were nearly zero.

Table 6 indicates that none of the variables studied significantly influenced the direct financial cost of care during an episode of disease. However, two trends must be noted. First, the cost of care was relatively high for patients with diseases in the categories of respiratory tract syndrome and diseases related to the WHS complex. Second, the poorest pay the same as the more wealthy patients for health care.

\section{Discussion}

As in other similar studies $[1,10]$, the merit of this work lies in its multi-stage sampling frame, which renders the findings representative of the population studied (33 HAs with at least seven households per HA), and rigor in the conduct of the survey. In addition, this survey offers a detailed and innovative description of the therapeutic itineraries of patients in an urban health care system.

However, two limitations of this study have to be pointed out. Firstly, the recruitment of interviewers among modern health professionals (i.e. nurses) who presented themselves as such to the interviewees may have led respondents to under-report the use of traditional medicine. Further investigation using appropriate techniques is needed to accurately estimate the importance of traditional medicine in Lubumbashi. Secondly, we did not examine the severity character of reported diseases, a variable which could have contributed to explain the choice of care.

\section{Reported health problems}

The profile of health problems reported in this study is in agreement with what has been described elsewhere in urban populations in developing countries [30]. Malaria and fevers of unknown origin and diseases of the respiratory and digestive tracts predominate $[1,2,30]$. In this study, one-third of all surveyed patients had suffered from malaria and/or fever during the study period. Although malaria syndrome is a commonly reported health problem, its frequency in our study is half of the one reported by Kakoma [18]. This difference may be explained by seasonal variations in disease incidence: our study took place in the dry season (July), a period of low transmission of malaria, while the Kakoma study was conducted during the rainy season (March-April), a period of high 
Table 3 Health problems reported by respondents, Lubumbashi 2010

\begin{tabular}{|c|c|c|c|c|c|}
\hline & Malaria syndrome $n=86$ & Resp. tract syndrome $n=70$ & Complex WHS $n=43$ & Others $\mathrm{n}=52$ & Total $\mathrm{n}=\mathbf{2 5 1}$ \\
\hline \multicolumn{6}{|c|}{ Acute/chronic disease $^{a}$} \\
\hline Acute & $84(38.7)^{b}$ & $67(30.9)$ & $41(18.9)$ & $25(11.5)$ & $217(100.0)$ \\
\hline Chronic & $2(5.9)$ & $3(8.8)$ & $2(5.9)$ & $27(79.4)$ & $34(100.0)$ \\
\hline \multicolumn{6}{|l|}{ Duration } \\
\hline$\leq 2$ weeks & $80(38.5)$ & $66(31.7)$ & $40(19.2)$ & $22(10.6)$ & $208(100.0)$ \\
\hline$>2$ weeks & $6(14.0)$ & $4(9.3)$ & $3(7.0)$ & $30(69.8)$ & $43(100.0)$ \\
\hline
\end{tabular}

${ }^{a}$ As reported by interviewee.

${ }^{\mathrm{b}}$ Figures between () are percentages.

transmission. Our study period may also explain the high frequency of respiratory tract syndrome, which was dominated by acute respiratory infections. The dry season in Lubumbashi is characterized by cold and dust, two factors that favour the development of these infections.

\section{Therapeutic options and patients' itineraries}

The health-seeking behaviour of patients in Lubumbashi is complex and involves both formal and informal care. Figure 2 indicates that patients used five different therapeutic options, either exclusively or in combination (i.e., sequentially), during the two weeks preceding the survey.

Self-medication with modern drugs is the initial therapeutic option chosen by the majority of inhabitants of Lubumbashi $(54.6 \%)$ when they face a health problem. This result is comparable to the respective frequencies of $55.6 \%$ and $58.5 \%$ observed in Ouagadougou [1] and Cotonou [10]. This practice is widespread in both rural [24,31-33] and urban areas [1,2,34]. The main reason for this practice is its affordability; it involves only the cost of the drugs that are purchased; the patient is thus exempt from other costs related to transportation, consultation of health workers, and various technical examinations [35]. Another reason for the high level of self-medication in the specific context of Lubumbashi may be the intrusive marketing of all sort of drugs via wall posters. Such posters are present in almost every single waiting room of a health worker, and are associated with easy access to drugs without prescription by a professional. In this context, self-medication is more likely to have medical (harmful to the patient) as well as economic consequences (spending money on sometimes non useful drugs). Therefore, the importance of self-

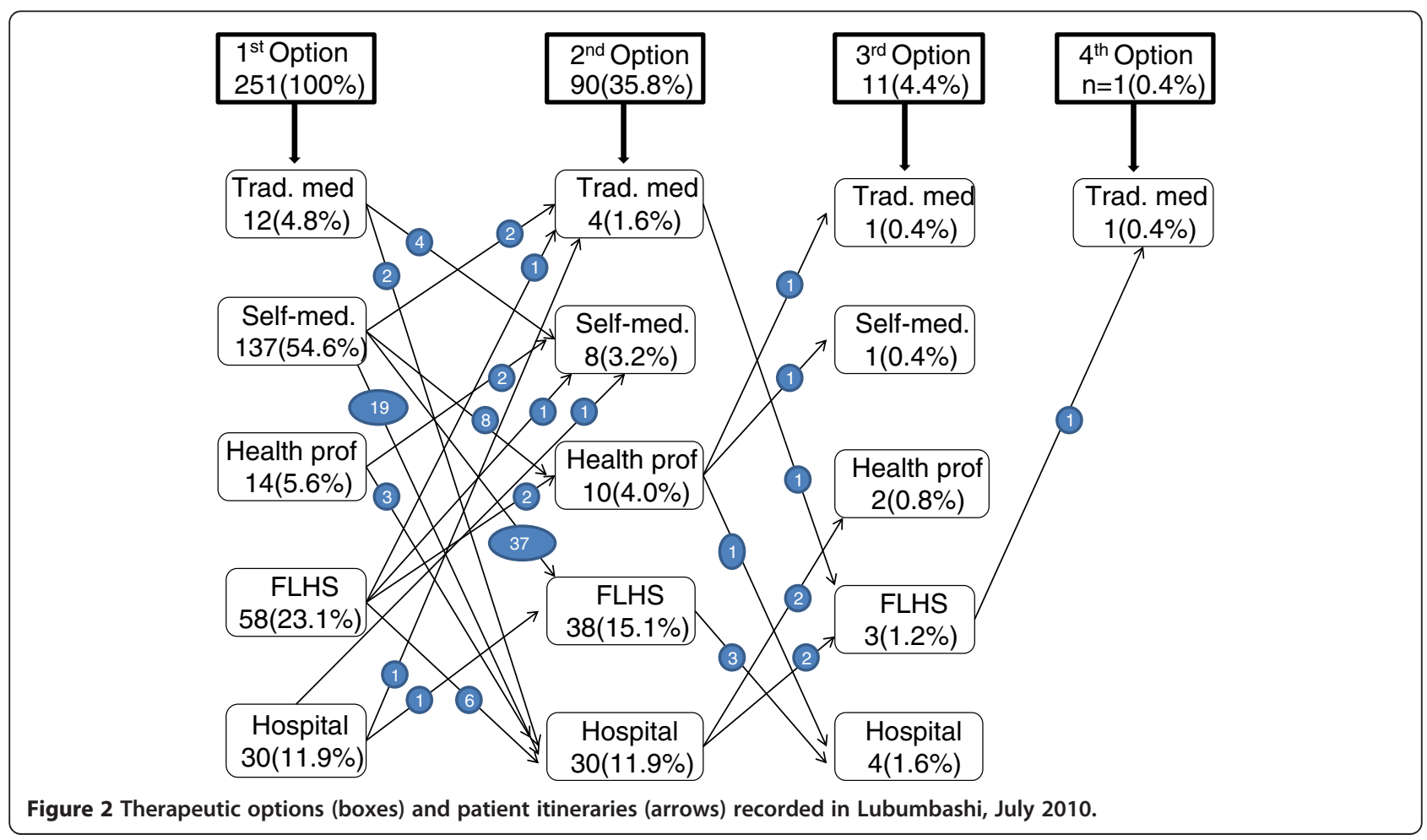


Table 4 Factors influencing the use of formal therapeutic options in Lubumbashi, 2010

\begin{tabular}{|c|c|c|c|c|c|}
\hline Factors & $\mathrm{n}=\mathbf{2 5 1}$ & Formal therapeutic options (\%) & OR & $95 \% \mathrm{Cl}$ & $\mathbf{p}$ \\
\hline Age (years) & & & & & 0.91 \\
\hline$\leq 4$ & 61 & 41.0 & 1.00 & & \\
\hline$\geq 5$ & 190 & 40.5 & 0.96 & $0.49-1.88$ & \\
\hline Sex & & & & & 0.47 \\
\hline Male & 105 & 39.1 & 1.00 & & \\
\hline Female & 146 & 41.8 & 1.16 & $0.77-1.76$ & \\
\hline Acute/chronic disease ${ }^{a}$ & & & & & 0.01 \\
\hline Acute & 217 & 37.3 & 1.00 & & \\
\hline Chronic & 34 & 61.8 & 2.52 & $1.25-5.09$ & \\
\hline Health problems & & & & & 0.35 \\
\hline Malaria syndrome & 86 & 36.0 & 1.00 & & \\
\hline Respiratory tract syndrome & 70 & 34.3 & 0.94 & $0.46-1.89$ & \\
\hline WHS complex & 43 & 46.5 & 1.41 & $0.65-3.07$ & \\
\hline Others & 52 & 51.9 & 1.75 & $0.84-3.64$ & \\
\hline Household size & & & & & 0.44 \\
\hline $1-5$ & 74 & 46.0 & 1.00 & & \\
\hline $6-10$ & 129 & 35.7 & 0.67 & $0.37-1.24$ & \\
\hline$\geq 11$ & 48 & 45.8 & 0.97 & $0.55-1.69$ & \\
\hline Number of parents in the household & & & & & 0.63 \\
\hline 1 & 6 & 50.0 & 1.00 & & \\
\hline 2 & 245 & 40.4 & 0.67 & $0.13-3.37$ & \\
\hline Level of education of household head & & & & & 0.23 \\
\hline Higher education & 55 & 32.7 & 1.00 & & \\
\hline High education & 145 & 40.7 & 1.34 & $0,67-2,69$ & \\
\hline Illiterate and Primary education & 51 & 49.0 & 1.78 & $0.83-3.81$ & \\
\hline Main income generating activity of the household head & & & & & 0.56 \\
\hline Corporate executives and professionals & 6 & 33.3 & 1.00 & & \\
\hline Salaried employees and independent workers & 139 & 44.6 & 1.61 & $0.28-9.15$ & \\
\hline Paid on a daily basis & 77 & 36.4 & 1.14 & $0.19-6.71$ & \\
\hline Inactive & 29 & 34.5 & 1.05 & $0.16-6.96$ & \\
\hline Socioeconomic status of the household & & & & & 0.18 \\
\hline 5 (Richest) & 48 & 41.7 & 1.00 & & \\
\hline 4 & 52 & 40.4 & 0.80 & $0.38-1.73$ & \\
\hline 3 & 39 & 33.3 & 0.74 & $0.33-1.67$ & \\
\hline 2 & 60 & 43.3 & 1.41 & $0.82-2.42$ & \\
\hline 1 (Poorest) & 52 & 42.3 & 0.75 & $0.40-1.40$ & \\
\hline
\end{tabular}

${ }^{\mathrm{a}}$ As reported by interviewee.

medication deserves special consideration, especially because this study also reveals that over one-half of those surveyed consider it to be effective. From a public policy point of view, it appears more appropriate to try to rationalize the practice than to attempt (often in vain) to prohibit it. In this context, one option would be to focus regulatory efforts on a limited list of drugs whose contraindications and risks are significant [5] and develop programs to promote self-medication practices for mild health problems. Experiments of this type of practice in the DR Congo have already been documented in the two rural HDs of Kasongo and Bwamanda [36].

The second most frequent initial therapeutic option taken by patients in Lubumbashi is the search for care in formal health facilities. Other similar studies in other cities of sub-Saharan Africa have made the same 
Table 5 Median costs (in USD ${ }^{a}$ ) for the components of care for each therapeutic option, Lubumbashi 2010 ( $\mathrm{n}=\mathbf{2 5 1}$ households)

\begin{tabular}{llll}
\hline $\begin{array}{l}\text { Therapeutic option/components } \\
\text { of care }\end{array}$ & $\mathbf{n}$ & $\begin{array}{l}\text { Median cost } \\
\text { (Q1-Q3) }\end{array}$ & $\mathbf{9 5 \%} \mathbf{C l}$ \\
\hline Traditional medicine & 14 & $0.4(0.0-3.9)$ & $0.0-2.0$ \\
$\begin{array}{l}\text { Self-medication } \\
\text { Self-employed private health professionals }\end{array}$ & 111 & $0.9(0.2-2.2)$ & $0.6-1.2$ \\
$\quad$ & 23 & $0.0(0.0-0.0)$ & $0.0-0.0$ \\
$\quad$ Transportation fees & 21 & $0.0(0.0-0.2)$ & $0.0-0.1$ \\
$\quad$ Consultation fees & 19 & $3.4(1.4-7.8)$ & $1.1-5.7$ \\
$\quad$ Cost of medicines & & & \\
FLHS & 100 & $0.0(0.0-0.0)$ & $0.0-0.0$ \\
$\quad$ Transportation fees & 68 & $2.2(1.2-2.8)$ & $2.2-2.3$ \\
$\quad$ Consultation fees & 67 & $2.2(0.0-3.9)$ & $1.5-3.0$ \\
$\quad$ Lab exams fees & 56 & $5.9(1.9-13.6)$ & $3.5-8.4$ \\
Cost of medicines & 78 & $0.0(0.0-0.0)$ & $0.0-0.0$ \\
Cost of observation & & & \\
Hospital & 50 & $1.4(0.0-3.6)$ & $0.6-2.2$ \\
Transportation fees & 32 & $3.3(0.0-5.2)$ & $1.9-4.8$ \\
Consultation fees & 26 & $1.1(0.0-5.6)$ & $0.0-2.8$ \\
Lab exams fees & 25 & $7.8(2.2-16.7)$ & $3.2-12.3$ \\
Cost of medicines & 35 & $0.0(0.0-0.0)$ & $0.0-0.0$ \\
\hline Hospitalization fees & & &
\end{tabular}

${ }^{\mathrm{a}} 1 \mathrm{USD}=900$ Congolese Francs.

observation $[1,10,34]$. In the present study, it was established that more than one-half of patients $(56.5 \%)$ who had a contact with a formal health care service as the first step in their health-seeking behaviour did so at the level of a FLHS. The FLHS is supposed to be the privileged entry point into the formal health care system in the DR Congo, and elsewhere [37]. Nevertheless, the proportion of patients who bypass the FLHS is quite high: $30.4 \%$ of patients who have used formal care as a first, second, or third option went directly to the hospital. Direct access to the hospital was employed as the first option for $11.9 \%$ of patients in Lubumbashi. However, in two studies comparable to ours, only $2.1 \%$ of patients in Ouagadougou [1] and $4.4 \%$ of patients in Cotonou [10] used the hospital as a first option. This difference is striking. In the urban environment of Lubumbashi, where geographical accessibility is not an issue [14], bypassing the FLHS usually reflects the open competition that exists between the two levels of care $[14,38,39]$. The reasons for the patients' attraction to the hospital in the context of Lubumbashi are not yet clear and should be investigated further in order to effectively reorganize health care in this city, especially given the perceived high effectiveness of formal care.

In our study, $7.2 \%$ of patients used traditional medicine at some point in their complex therapeutic itinerary. This
Table 6 Factors influencing the total direct financial cost (in USD ${ }^{a}$ ) in the management of an episode of illness, Lubumbashi 2010

\begin{tabular}{|c|c|c|c|}
\hline Variables & $\mathrm{n}=95^{\mathrm{b}}$ & $\begin{array}{l}\text { Median cost } \\
\text { (Q1-Q3) }\end{array}$ & $95 \% \mathrm{Cl}$ \\
\hline \multicolumn{4}{|l|}{ Age } \\
\hline$\leq 4$ & 18 & $2.6(1.0-11.5)$ & $0.0-6.5$ \\
\hline$\geq 5$ & 77 & $8.9(2.5-18.3)$ & $6.0-11.7$ \\
\hline \multicolumn{4}{|l|}{ Sex } \\
\hline Male & 39 & $8.7(1.7-21.5)$ & $3.6-13.7$ \\
\hline Female & 56 & $6.5(2.4-14.3)$ & $4.0-9.0$ \\
\hline \multicolumn{4}{|l|}{ First therapeutic option } \\
\hline Informal & 57 & $5.7(1.3-13.5)$ & $2.5-8.8$ \\
\hline Formal & 38 & $8.9(1.8-19.4)$ & $5.2-12.6$ \\
\hline \multicolumn{4}{|l|}{ Number of therapeutic options used } \\
\hline 1 & 58 & $3.3(1.7-13.3)$ & $0.0-11.6$ \\
\hline 2 & 32 & $7.4(1.7-23.4)$ & $2.3-12.6$ \\
\hline 3 & 5 & $8.8(2.5-15.0)$ & $6.2-11.4$ \\
\hline \multicolumn{4}{|l|}{ Health problems } \\
\hline Malaria syndrome & 31 & $3.9(1.0-15.8)$ & $1.1-6.7$ \\
\hline Respiratory tract syndrome & 23 & $8.9(2.7-13.7)$ & $6.0-11.8$ \\
\hline WHS complex & 15 & $10.7(3.5-26.9)$ & $3.4-17.9$ \\
\hline Others & 26 & $7.5(2.0-14.7)$ & $4.8-10.2$ \\
\hline
\end{tabular}

Level of education of household head

Illiterate and primary education

Secondary education

22

$11.3(2.6-18.8) \quad 5.8-16.7$

Higher education

$48 \quad 5.3(1.1-17.1) \quad 1.6-8.9$

$25 \quad 9.8(3.3-15.6) \quad 5.9-13.6$

Socioeconomic status of the

household

$\begin{array}{llll}1 \text { (Poorest) } & 20 & 8.8(4.6-15.4) & 5.0-12.6 \\ 2 & 23 & 9.4(1.7-24.6) & 1.9-17.0 \\ 3 & 17 & 6.1(1.7-36.1) & 0.0-19.3 \\ 4 & 20 & 8.2(2.6-15.1) & 3.8-12.7 \\ 5 \text { (Richest) } & 15 & 4.9(1.7-11.6) & 0.9-8.9\end{array}$

${ }^{\mathrm{a}} 1$ USD $=900$ Congolese Francs.

${ }^{\mathrm{b}}$ This figure represents the number of surveyed patients whose disease episode was finished at the time of survey, and who indicated the total amount spent during the episode.

is slightly lower than the $8.5 \%$ observed by Kakoma [18] 10 years ago in the same city. The use of traditional medicine was the first step in the therapeutic itinerary for $4.8 \%$ of patients. In two comparable surveys conducted in Ouagadougou and Cotonou more than 10 years ago, the rates of use of traditional medicine as a first option were, respectively, $2.4 \%$ and $0.4 \%[1,10]$. According to another survey conducted in Cotonou, nearly $30 \%$ of hospitalized patients had used a traditional remedy before hospitalization [24]. The WHO [40] and UNAIDS [41] estimate that $80-85 \%$ of the rural and urban sub-Saharan 
population use traditional medicine. The increasing dominance of modern medicine is one possible explanation for the low use of traditional medicine, at least as a first option, observed in our study. However, an examination of patients' therapeutic itineraries indicates that formal care is the last resort of patients seeking care in the city of Lubumbashi.

\section{Determinants of therapeutic itineraries in Lubumbashi}

Contrary to our expectations (Figure 1), no statistically significant association was observed between the dependent variable (use of formal care) and most of the independent variables (Table 4). Other studies have shown that all of these variables can influence health-seeking behaviour [3,42-45], even if the influence of some of these variables on the choice of therapeutic options is divergent. A study in Guinea-Conakry has shown that children and women preferentially seek care in public health centres, while men rather attend private pharmacies [46]. However, similarly to our study, other studies have shown that sex, household size, education level, and occupation of the head of household do not influence the choice of care $[1,8]$. Studies also diverge on the recognition of socioeconomic status as a determinant of therapeutic choice. Although some report that high socioeconomic status is a major determinant of the use of modern health care $[1,45,47]$, our findings do not confirm this.

Our study indicates that the nature of a health problem does not determine patients' therapeutic choices. But, if patients acknowledge that they have a chronic disease, they rather seek formal care than for an acute disease. The validity of this finding is confirmed when looking at the result of cross check with the duration of disease. This further strengthens the finding that formal care is the ultimate recourse for patients in search for health.

\section{Cost of care}

As reported in other studies [35,48,49], our research points to the importance of drugs in health expenditure. Unsurprisingly, using FLHS and hospitals leads to a higher expenditure for drugs than does self-medication. The lack of rationalization of drug prescription, which is exemplified by the over-prescription of antibiotics with regular prescription of more than four drugs, and the prescription of specialty drugs rather than generics, contributes to the high expenditure for drugs [50,51]. Indeed, Kasongo [51] showed that cefotaxime, a thirdgeneration cephalosporin antibiotic, is the antibiotic most often prescribed in two major hospitals in Lubumbashi. Although our study did not investigate the details of the practice of self-medication as it occurs in Lubumbashi, we hypothesize that self-medication may be inadequate because cost of drug creates a barrier that prevents people from taking them at the appropriate dosage and for a sufficiently long period of time.

The results of our study clearly indicate that the total financial cost of an episode of disease is not significantly influenced by any of the analyzed variables. However, a number of trends with respect to health care expenditure deserve to be commented. The relatively high cost of care regarding diseases related to the respiratory tract syndrome and to the WHS complex can only be explained by the high cost of drugs, including the lack of generic antibiotics [50,51]. Surprisingly, the cost of care does not differ statistically between sub-populations of different socioeconomic status, and the poorest pay the same as the more wealthy patients. This finding clearly points to the regressive nature of the health care payments in Lubumbashi, which leads to greater impoverishment of the poorest people, as has been reported by other authors $[49,52,53]$.

\section{Conclusions}

Self-medication as a widely spread practice must be rationalized. This process must be part of a more comprehensive drug policy program that should promote the effective use of generic and essential drugs of sound quality. Although formal care is not the most widely used initial therapeutic option, it is the last resort for most patients who appreciate its effectiveness, especially when they believe having a chronic disease. Therefore, decision makers should improve its access to the general population. Current therapeutic itineraries of patients in the health care system of the city of Lubumbashi are complex, but still favourable to the organization of an efficient referral system to ensure continuity of care and complementarities between different levels of care (individual/community, FLHS, hospital). Finally, the highly regressive nature of the current payment system of care calls for dramatic reform to promote mechanisms of universal access to care to ensure solidarity and equity. Our study provides evidences for such actions.

\section{Competing interests}

The authors declare that they have no competing interests.

\section{Authors' contributions}

MFC, JVDV, W, and BC conceptualized the study and designed the questionnaire. MFC supervised the data collection and did data validation. W performed the statistical analysis. MFC drafted the manuscript. JVDV, NOL, MAM, and BC reviewed critically the manuscript. BC supervised the overall research. All authors read and approved the final manuscript.

\section{Acknowledgements}

The authors thank the Belgian University Commission for Development for its financial support to this study and the Institute of Tropical Medicine in Antwerp for its help in the writing of this paper. 


\section{Author details}

${ }^{1}$ Ecole de santé publique, Université de Lubumbashi, P.O. Box 1825 , Lubumbashi, RD, Congo. '2Department of Public Health, Institute of Tropical Medicine, Nationalestraat 155, 2000 Antwerp, Belgium. ${ }^{3}$ Ecole de Santé Publique, Université de Kinshasa, P.O. Box 11850, Kinshasa I, RD, Congo.

Received: 19 June 2013 Accepted: 8 April 2014

Published: 15 April 2014

\section{References}

1. Develay A, Sauerborn R, Diesfeld HJ: Utilization of health care in an African urban area: results from a household survey in Ouagadougou, Burkina Faso. Soc Sci Med 1996, 43:1611-1619.

2. Harpham T, Molyneux C: Urban health in developing countries: a review. Prog Dev Stud 2001, 1:113-137

3. Shaikh BT, Hatcher J: Health Seeking Behaviour and Health Service Utilization in Pakistan: Challenging the Policy Makers. J Public Health 2004, 27: 49-54.

4. Mahmood SS, labal M, Hanifi SMA: Health-Seeking Behaviour. In Health for the Rural Masses, Insights from Chakaria. Edited by Bhuiya A. Dhaka: International Centre for Diarrhoeal Disease Research, Bangladesh (ICDDR, B); 2009:67-93.

5. Meessen B, Bigdeli M, Chheng K, Decoster K, Ir P, Men C, Van Damme W Composition of pluralistic health systems: how much can we learn from household surveys? An exploration in Cambodia. Health Policy Plan 2011, 26(Suppl 1):i30-i44.

6. Sato A: Revealing the popularity of traditional medicine in light of multiple recourses and outcome measurements from a user's perspective in Ghana. Health Policy Plan 2012, 27:625-637.

7. Kroeger A: Introduction to the Methodology of Household Surveys. In Training Modules of Household Surveys on Health and Nutrition. Edited by WHO. Geneva: WHO; 1988:3-11.

8. Vidal L: Itinéraire thérapeutique et connaissance de la maladie chez des patients séropositifs pour le VIH (Abidjan, Côte-d'Ivoire). Cahiers Santé 1992, 2:320-329.

9. Diallo BA: Itinéraires thérapeutiques et coût de I'HTA en milieu urbain malien. Med Afr Noire 1994, 41:106-107.

10. Gomes do Espirito Santo E, Floury B, Cissé M: Déterminants du recours aux soins dans la ville de Cotonou (Bénin). Bulletin OMS 1998, 76:195-201.

11. Grodos D: Le District Sanitaire Urbain en Afrique sub-Saharienne: Enjeux, Pratiques et Politiques [Thèse de Doctorat en Santé Publique] Université Catholique de Louvain, Faculté de Médecine, Département de Santé Publique; 2000.

12. Harpham T, Burton $S$, Blue I: Healthy city projects in developing countries: the first evaluation. Health Promot Int 2001, 16:111-125.

13. Cadot $E$, Harang $M$ : Offre de soins et expansion urbaine, conséquences pour l'accès aux soins. L'exemple d'Ouagadougou (Burkina Faso). Espace Popul Soc 2006, 2-3:329-339.

14. Chenge M, Van der Vennet J, Porignon D, Luboya NO, Kabyla I, Criel B: La carte sanitaire de la ville de Lubumbashi, République Démocratique du Congo. Partie I: problématique de la couverture sanitaire en milieu urbain congolais. Glob Health Promot 2010, 17:63-74.

15. Wembonyama S, Mpaka S, Tshilolo L: Médecine et Santé en République Démocratique du Congo: de l'indépendance à la 3è République. Med Trop 2007, 67:447-457.

16. Institut National de Statistiques et Unicef: Enquête par Grappes à Indicateurs Multiples en RD Congo 2010: Rapport Final. Kinshasa; 2011. [http://www. unicef.org/drcongo/french/MICS_RDC_2010.pdf]

17. Ministère du Plan, Macro International: Enquête Démographique et de Santé, République Démocratique du Congo 2007. Calverton, Maryland, U.S.A: Ministère du Plan et Macro International; 2008.

18. Kakoma S: Le Profil Sanitaire du Lushois: Rapport des Recherches Effectuées Durant la Troisième Session des Travaux de l'observatoire du Changement Urbain, Février-Juin 2001. Lubumbashi: Presses universitaires de Lubumbashi; 2002.

19. Chenge $M$, Kalenga MK, Kakoma SZ: Les états fébriles chez les gestantes à Lubumbashi (République Démocratique du Congo). Rev Fr Gynecol Obste 1998, 93:475-480

20. Yaba A: Paludisme Grave Chez l'enfant: Etude Clinique, Parasitologique, Biologique et Anthropométrique à Lubumbashi. Cas de Cliniques Universitaires de Lubumbashi. [Mémoire de Spécialisation en Pédiatrie]. Faculté de Médecine, Université de Lubumbashi; 2007.

21. Kizonde K, Kinenkinda X, Kimbala J, Kamwenyi K: La césarienne en milieu africain: exemple de la maternité centrale Sendwe de Lubumbashi, RD Congo. Med Afr Noire 2006, 53:293-298.

22. Kakoma S, Muyumba K, Mwamba M: Prévalence de I'hypertension artérielle dans la population Congolaise de Lubumbashi. Lub Med 2002, 3:18-21.

23. Chenge M, Van der Vennet J, Porignon D, Luboya N, Kabyla I, Criel B: La carte sanitaire de la ville de Lubumbashi, République Démocratique du Congo. Partie II: analyse des activités opérationnelles des structures de soins. Glob Health Promot 2010, 17:75-84.

24. Richard JL: Accès et Recours aux Soins de Santé Dans la Sous Préfecture de Ouessè (Bénin) [Thèse de Doctorat en Géographie de la Santé] Faculté des Lettres et Sciences Humaines de l'université de Neuchâtel; 2001.

25. Fassin $D$, Brouselle $C$ : Les enquêtes d'accès aux soins en Afrique. Problèmes méthodologiques. Rev Epidém et Santé Pub/ 1991, 39:89-99.

26. Wyss K, Sy I, Cisse G, Tanner M: Urbanisation et santé à Rufisque (Sénégal). Enjeux et perspectives dans une ville de l'Afrique de l'Ouest. Bulletin von Medicus Mundi Schweiz 2008, 110:20-25.

27. Petit P: Ménages de Lubumbashi, Entre Précarité et Recomposition. Paris: L'Harmattan; 2003.

28. Kleinbaum DG, Kupper LL, Muller KE, Nizam A: Applied Regression Analysis and Other Multivariable Methods. 3rd edition. Brooks/Cole Publishing Company; 1998.

29. Donner A, Klar N: Design and Analysis of Cluster Randomization Trials in Health Research. London: Arnold, a member of the Hodder Headline Group; 2000.

30. Harpham T: Review article: health and the urban poor. Health Policy Plan 1986, 1:5-18.

31. Young JC, Garro LY: Variation in the choice of treatment in two Mexican communities. Soc Sci Med 1982, 16:1453-1465.

32. Van der Geest S: Self care and the informal sale of drugs in south Cameroon. Soc Sci Med 1987, 25:293-305.

33. Sauerborn R, Nougtara A, Diefeld HJ: Low utilization of community health workers: results from a household interview survey in Burkina Faso. Soc Sci Med 1989, 29:1163-1174.

34. Assani A: Etude de l'équité et de l'accès à des Soins de Qualité en Milieu Urbain Dans Cinq Capitales de l'Afrique de l'Ouest: Abidjan. Conakry, Dakar et Niamey. Rapport synthèse rédigé dans le cadre d'une consultance dans la phase de recherche-action du projet Santé Urbaine financé par I'UNICEF et la Coopération française: Bamako; 2001

35. Hamel MV: La Vente Illicite de Médicaments dans les Pays en Développement: Analyse de l'émergence d'un Itinéraire Thérapeutique à Part Entière, Situé en Parallèle du RecoursClassique aux Structures Officielles de Santé. [Thèse de doctorat]. Université Claude-Bernard-Lyon I, Faculté de Pharmacie; 2006.

36. Criel B: Self-Medication With Western Pharmaceuticals in Developing Countries. Attempts of its Integration in Primary Health Care: Discussion of two Experiences in Zairre. Lessons for the Future? [Master's Thesis]. London School of Hygiene and Tropical Medicine, University of London; 1989.

37. Ministère de la santé/Secrétariat Général: Recueil des Normes de la Zone de Santé. Kinshasa, République Démocratique du Congo; 2006 [http://www. minisanterdc.cd/Articles/NORMES\%20DE\%20LA\%20ZS\%20(VERSION\% 20FINALE).doc.]

38. Kachirayam M, Radhakrishna S, Ramanathan AM, Jabbar S, Ezhil R: Utilization of health services in Madras City. Indian J Med Res 1986, 83:96-105.

39. Kloos H, Etea A, Degefa A, Aga H, Solomon B, Abera K, Abegaz A, Belemo G: Illness and health behaviour in Addis Ababa and rural central Ethiopia. Soc Sci Med 1987, 25:1003-1019.

40. WHO: WHO Traditional Medicine Strategy 2002-2005. Avalaible from: http://www.who.int/medicines/publications/traditionalpolicy/en/index.html.

41. UNAIDS: Collaborating With Traditional Healers for HIV Prevention and Care in sub-Saharan Africa: Suggestions for Programme Managers and Field Workers. Geneva: UNAIDS; 2006

42. Yip WC, Wang H, Liu Y: Determinants of choice of medical provider: a case study in rural China. Health Policy Plan 1998, 13:311-322.

43. Goldman JN, Heuveline P: Health seeking behavior for child illness in Guatemala. Trop Med Int Health 2000, 5:145-155.

44. Thorson A, Hoa NP, Long NH: Health seeking behavior of individuals with a cough of more than 3 weeks. Lancet 2000, 356:1823-1824. 
45. Nyamongo IK: Health care switching behavior of malaria patients in a Kenyan rural community. Soc Sci Med 2002, 54:377-386.

46. Leach MA, Fairhead JR, Millimouno D, Diallo AA: New therapeutic landscapes in Africa: parental categories and practices in seeking infant health in the Republic of Guinea. Soc Sci Med 2008, 66:2157-2167.

47. Asenso-Okyere WK, Anum A, Osei-Akoto I, Adukoni A: Cost recovery in Ghana: are there any changes in health care seeking behaviour? Health Policy Plan 1998, 13:181-188.

48. Tchitchoua J: Accès aux Soins et aux Médicaments, Formes de Recours et Comportements Thérapeutiques au Cameroun. In Rapport du ième Colloque International sur le Développement Durable et Santé dans les Pays du Sud. Lyon: Centre Européen pour la Santé Humanitaire; 2005. 9 décembre 2005.

49. Wahed T, Mahmood SS: Costs of Utilization of Health Services. In Health for the Rural Masses, Insights from Chakaria. Edited by Bhuiya A. Dhaka: International Centre for Diarrhoeal Disease Research, Bangladesh (ICDDR, B); 2009:95-113.

50. Van Olmen J, Criel B, Bhojani U, Marchal B, Van Belle S, Chenge MF, Hoerée T, Pirard M, Van Damme W, Kegels G: The health system dynamics framework: the introduction of an analytical model for health system analysis and its application to two case-studies. Health, Culture and Society 2012, 2(1):1-21.

51. Kasongo K: Estimation de la Prévalence des Infections Nosocomiales à I'hôpitalProvincial de Référence Janson Sendwe et aux Cliniques Universitaires de Lubumbashi, RD Congo. [Mémoire de Master en Santé Publique]. Université Libre de Bruxelles, Ecole de Santé Publique; 2011.

52. Londono JL, Frenk J: Structured pluralism: towards an innovative mode for health system reform in Latin America. Health Policy 1997, 41:1-36.

53. Bhojani U, Thriveni BS, Devadasan R, Munegowda CM, Devadasan N, Kolsteren P, Criel B: Out-of-pocket healthcare payments on chronic conditions impoverish urban poor in Bangalore, India. BMC Public Health 2012, 12:990.

doi:10.1186/1472-6963-14-173

Cite this article as: Chenge et al:: Health-seeking behaviour in the city of Lubumbashi, Democratic Republic of the Congo: results from a cross-sectional household survey. BMC Health Services Research 2014 14:173.

\section{Submit your next manuscript to BioMed Central and take full advantage of:}

- Convenient online submission

- Thorough peer review

- No space constraints or color figure charges

- Immediate publication on acceptance

- Inclusion in PubMed, CAS, Scopus and Google Scholar

- Research which is freely available for redistribution 